\title{
Renal Replacement Therapy in Patients over 65 Years 0ld
}

\author{
Imen Gorsane, Madiha Mahfoudhi*, Mondher Ounissi, Fathi Younsi, Imed Helal, \\ Taieb Ben Abdallah \\ Internal Medicine A Department, Charles Nicolle Hospital, Tunis, Tunisia \\ Email: ${ }^{*}$ madiha mahfoudhi@yahoo.fr
}

Received 31 March 2015; accepted 7 June 2015; published 10 June 2015

Copyright (C) 2015 by authors and Scientific Research Publishing Inc.

This work is licensed under the Creative Commons Attribution International License (CC BY). http://creativecommons.org/licenses/by/4.0/

(c) (†) Open Access

\begin{abstract}
Age at onset of renal replacement therapy (RRT) is increasing in all countries. Two substitution methods of renal function remain available: hemodialysis (HD) and peritoneal dialysis (PD). It was a retrospective study carried out on January 2015 and it included patients older than 65 years, monitored for HD and PD. We studied their epidemiological and clinical profile, their evolution, and the elements of prognosis. Two groups of 42 patients were included. The first was about $30 \mathrm{HD}$ patients representing $25 \%$ of all patients on HD with an average age of $71 \pm 4.5$ years. The second was concerning 12 patients on PD having a mean age of $69.8 \pm 3.5$ years and representing $11.7 \%$ of all patients on PD. Functional and vital prognosis of a patient with end stage renal disease (ESRD) depends, in the elderly, on psychological, cognitive functions, and the degree of autonomy.
\end{abstract}

\section{Keywords}

Renal Replacement Therapy, Elderly, Hemodialysis, Peritoneal Dialysis

\section{Introduction}

The aging of the current population and future is recognized by all demographic studies. The health professional currently holds the age of 75 to define an old person.

The incidence of end stage renal disease and age at onset of renal replacement therapy (RRT) is increasing in all countries. The number of older patients requiring dialysis therapy is rising, reflecting the ageing of the general population [1]. Kidney transplantation is not generally given to this category of the population, two substitution methods of renal function remain available: HD and PD.

We report our experience of care in RRT of the elderly population.

\footnotetext{
"Corresponding author.
}

How to cite this paper: Gorsane, I., Mahfoudhi, M., Ounissi, M., Younsi, F., Helal, I. and Abdallah, T.B. (2015) Renal Replacement Therapy in Patients over 65 Years Old. Open Journal of Nephrology, 5, 44-48. 


\section{Material and Methods}

It was a single-center retrospective study carried out in our department of nephrology, in January 2015 and included patients older than 65 years in RRT: HD and PD.

Exclusion criteria: Patients on hemodialysis for less than 3 months and patients with acute infection, or active neoplasia.

We studied their epidemiological and clinical profile, the different complications during RRT and the elements of the prognosis.

Clinical, biological and radiological parameters were identified from medical records. Patient's records were point data of patients at the time of the study in January 2015.

The ethics committee had no objections against this study since it reflects our clinical work habits and did not include supplementary measures (other biological or radiological examinations).

We performed a comparative study of these parameters between patients on HD and those in PD.

Baseline characteristics were described as means and standard deviations for continuous variables, and frequencies and proportions for categorical variables.

A study of the correlation was made between the various parameters by the statistical test CHI2. $P$ value $\leq$ 0.05 was regarded as significant.

\section{Results}

Two groups of patients were included.

For the first group, there were 30 chronic HD patients, 13 women and 17 men representing $25 \%$ of all patients on HD. The average age was $71 \pm 4.5$ years. The initial nephropathy was vascular nephropathy in 7 cases, diabetic nephropathy in 11 cases, indeterminate nephropathy in 5 cases, chronic interstitial nephritis in 5 cases and nephropathy secondary to polycystic kidney disease in 2 cases. The age of initiation of hemodialysis was $69 \pm$ 3.5 years.

Vascular access was an arteriovenous fistula (AVF) in 16 cases, an AV graft (AVG) in 2 cases and a tunneled catheter in 2 cases. Seven patients were anuric, 14 patients were oliguric and 9 patients had residual diuresis.

The number of sessions per week was 3 times in 8 cases, 2 times in 11 cases and only one session per week in 11 cases.

Several patients had comorbidities with myocardial infarction in 4 cases, heart rhythm disorder in 3 cases, sleep apnea syndrome in 2 cases, and dementia in 2 cases.

Fifteen patients were not autonomous. The impossibility of walking was observed in 3 cases, a limitation of walking in 7 cases, bilateral blindness in one case, and decreased auditory acuity in 4 cases.

The average hemoglobin $(\mathrm{Hb})$ was $8.28 \pm 1.9 \mathrm{~g} / \mathrm{dl}$, the mean serum cholesterol was $3.98 \pm 1.01 \mathrm{mmol} / \mathrm{l}$, the mean triglyceride level was $1.29 \pm 0.9 \mathrm{mmol} / \mathrm{l}$, the mean serum calcium was $2.1 \pm 0.4 \mathrm{mmol} / \mathrm{l}$, the mean serum phosphorus was $1.46 \mathrm{mmol} / \mathrm{l} \pm 0.5$, the mean parathyroid hormone (PTH) was $848.07 \pm 490 \mathrm{pg} / \mathrm{ml}$, the mean serum albumin was $31 \pm 4.2 \mathrm{~g} / \mathrm{l}$.

Hemodynamic tolerance of hemodialysis was good in 14 cases only. Two deaths occurred following a cardiovascular complication.

The second group was concerning 12 patients on PD: 7 men and 5 women, having a mean age of $69.8 \pm 3.5$ years and representing $11.7 \%$ of all patients on PD. Seven were on automatic peritoneal dialysis and 5 on continuous ambulatory peritoneal dialysis. Kidney diseases were diabetes nephropathy in $58.3 \%$ of cases and vascular nephropathy in $41.6 \%$ of cases. Patients were not autonomous, they were helped by their children in $62.5 \%$ of cases and their partners in 38.5\% of cases. Comorbidity was important: hypertension $91.6 \%$ of cases; Diabetes $66.6 \%$ of cases and heart disease $33.3 \%$ of cases.

Peritonitis was present in 5 cases, recurrent in 1 case. Staphylococcus was the causative organism in 3 cases.

The average biological values were: Hb: $9.6 \pm 0.9 \mathrm{~g} / \mathrm{dl}$, Albumin: $27 \pm 2.6 \mathrm{~g} / \mathrm{l}$, cholesterol: $4.1 \pm 1 \mathrm{mmol} / \mathrm{l}$, triglyceride: $1.09 \pm 1.2 \mathrm{mmol} / \mathrm{l}$, Serum Calcium: $2.21 \pm 0.28 \mathrm{mmol} / \mathrm{l}$, phosphorus: $1.79 \pm 0.15 \mathrm{mmol} / \mathrm{l}$ and PTH: $524 \pm 378 \mathrm{pg} / \mathrm{ml}$.

One death occurred after a bronchopulmonary infection.

The differences on Socio-demographic characteristics, comorbidities and biological data between the 2 groups are presented in Table 1.

They were not statistically significant except for albumin level. 
Table 1. Clinical and biological parameters.

\begin{tabular}{cccc}
\hline & HD $\mathbf{( N = 3 0 )}$ & PD (N = 12) & P \\
\hline Age (Years) & $71 \pm 4.5$ & $69.8 \pm 3.5$ & 0.1 \\
Sex (M/F) & $17 / 13$ & $7 / 5$ & 0.15 \\
Diabetes (\%) & $11(36.66 \%)$ & $8(66.66 \%)$ & 0.09 \\
HTA (\%) & $7(23.33 \%)$ & $11(91.66 \%)$ & 0.8 \\
Heart Disease (\%) & $7(23.33 \%)$ & $4(33.33 \%)$ & 0.5 \\
Dementia (\%) & $2(0.06 \%)$ & 0.9 \\
No autonomy (\%) & $15(0.5 \%)$ & $8(66.66 \%)$ & 0.1 \\
Death (\%) & $2(6.66 \%)$ & $1(8.33 \%)$ & 0.9 \\
Hemoglobin (g/dl) & $8.28 \pm 1.9$ & $9.6 \pm 0.9$ & 0.75 \\
Albumin (g/l) & $31 \pm 4.2$ & $27 \pm 2.6$ & $\mathbf{0 . 0 5}$ \\
Calcium (mmol/) & $2.1 \pm 0.4$ & $2.21 \pm 0.28$ & 0.8 \\
Phosphorus (mmol/l) & $1.46 \pm 0.5$ & $1.79 \pm 0.15$ & 0.5 \\
PTH (pg/ml) & $848.07 \pm 490$ & $524 \pm 378$ & 0.07 \\
Cholesterol (mmol/l) & $3.98 \pm 1.01$ & $4.1 \pm 1$ & 0.1 \\
Triglyceride (mmol/l) & $1.29 \pm 0.9$ & $1.09 \pm 1.2$ & 0.5 \\
\hline
\end{tabular}

\section{Discussion}

Reduced mortality and morbidity, prolongation of the patient's life, and better clinical outcomes of RRT allowed having older patients regularly monitored in dialysis units.

The age of patients with end-stage renal disease is increasing in all countries. The dialysis population is old with a median age mostly in the 60s and even over 70 years in some European regions [2]. In France, patients older than 75 years represent $40 \%$ of the patients who start RTT [3]. In Belgium, patients above 75 years comprise $41 \%$ of dialysis patients, as compared to $20 \%$ in the United Kingdom and $17 \%$ in Japan [4].

Older dialysis patients have a tendency to present later for dialysis, have a higher number of comorbid conditions, are at higher risk of cognitive dysfunction, impaired physical function, falls, poor nutrition and have increased levels of frailty [5] [6].

Old patients with terminal chronic renal failure can be offered conservative medical treatment or active renal replacement therapy. Advanced dementia and severe neurological sequels of stroke were shown as the conditions underlying the nephrologists' decision making not to provide dialysis in elderly patients [7].

The demographic, psychological, and health-related factors create a net of interdependences. Elderly patients with complex medical problems are a challenge to the health care team, clearly requiring the cooperation of physician, nurse, dialysis technician, social worker, dietician, physical medicine specialist, and a host of other subspecialists [8].

Many older patients do not have the opportunity for transplantation, so quality of life (QOL) in RRT is particularly important. The choice of dialysis modality has a major impact on many aspects of an individual's life [9].

A prospective study of incident and prevalent patients starting on dialysis over the age of 70 years, is the only study to have focused on older patients showed that outcomes, survival and QOL were not different for patients on HD and PD [10] [11].

The perception that older patients are more likely to have barriers to PD related to physical problems, social circumstances and cognitive dysfunction can result in the healthcare team believing that PD at home is not feasible in this patient group [12].

No difference in the course of functional status was observed between patients treated with PD or HD [13].

PD confers a substantial advantage in reducing rates of hospitalization for sepsis as compared with HD with 
central venous catheters among many older patients [14].

Risks and benefits of vascular access strategies in patients with differing life expectancies are controversial. AVF do not result in a lower lifetime risk of bacteremia compared with AVG in older patients without a permanent access at onset of ESRD, and that only those with longer life expectancy will benefit from pre-emptive AVF placement [14].

In our study, the differences on socio-demographic characteristics, comorbidities and biological data between the 2 groups of patients (HD and PD) were not statistically significant except for albumin level. This is probably due to the fact that there is a loss of albumin greater on DP compared to HD which adds to the poor nutrition on the elderly. However retrospective nature of our analysis and the small number of patients precludes any meaningful conclusion.

Recent studies suggested that dialysis provided a survival advantage compared to conservative management for most of stages 4 - 5 of chronic kidney disease patients over the age of 75. However, this advantage was lost for patients with multiple co-morbidities and ischemic heart disease [15] [16].

Regardless of the treatment choice, a multidisciplinary and multidimensional approach in the care of these patients is strongly needed [17].

\section{Conclusions}

Nephrologists are increasingly confronted with an elderly population of patients who have a large number of comorbid conditions requiring ongoing care.

Older patients on dialysis have unique needs and characteristics, and their outcomes vary from that of their younger counterparts.

RRT decision in the elderly requires consideration of functional and cognitive impairment and cardiovascular disease.

Both life expectancy and life quality should be taken into account.

Our results cannot be generalized because of the small size of our series.

\section{Conflict of Interest}

There are no conflicts of interest.

\section{References}

[1] Berger, J.R. and Hedayati, S.S. (2012) Renal Replacement Therapy in the Elderly Population. Clinical Journal of the American Society of Nephrology, 7, 1039-1046. http://dx.doi.org/10.2215/CJN.10411011

[2] ERA-EDTA (2009) 2007 ERA-EDTA Annual Report. Ann Rep, 21 September 2009.

[3] Moranne, O., Couchoud, C. and Vigneau, C. (2012) Characteristics and Treatment Course of Patients Older than 75 Years, Reaching End-Stage Renal Failure in France. The PSPA Study. The Journals of Gerontology: Series A, 67, 1394-1399. http://dx.doi.org/10.1093/gerona/gls162

[4] Canaud, B., Long, T., Tentori, F., Akiba, T., Karaboyas, A., Gillespie, B., et al. (2011) Clinical Practices and Outcomes in Elderly Hemodialysis Patients: Results from the Dialysis Outcomes and Practice Patterns Study (DOPPS). Clinical Journal of the American Society of Nephrology, 6, 1651-1662. http://dx.doi.org/10.2215/CJN.03530410

[5] Kimmel, P.L., Cohen, S.D. and Weisbord, S.D. (2008) Quality of Life in Patients with End-Stage Renal Disease Treated with Hemodialysis: Survival Is Not Enough! Journal of Nephrology, 21, S54-S58.

[6] Anand, S., Kurella Tamura, M. and Chertow, G.M. (2010) The Elderly Patients on Hemodialysis. Minerva Urologica e Nefrologica, 62, 87-101.

[7] Clement, R., Chevalet, P., Rodat, O., Ould-Aoudia, V. and Berger, M. (2005) Withholding or Withdrawing Dialysis in the Elderly: The Perspective of a Western Region of France. Nephrology Dialysis Transplantation, 20, 2446-2452. http://dx.doi.org/10.1093/ndt/gfi012

[8] Stel, V.S., Kramer, A., Zoccali, C. and Jager, K.J. (2009) The 2006 ERA-EDTA Registry Annual Report: A Precis. Journal of Nephrology, 22, 1-12.

[9] Tamura, M.K., Tan, J.C. and O’Hare, A.M. (2012) Optimizing Renal Replacement Therapy in Older Adults: A Framework for Making Individualized Decisions. Kidney International, 82, 261-269.

http://dx.doi.org/10.1038/ki.2011.384 
[10] Harris, S.A., Lamping, D.L., Brown, E.A. and Constantinovici, N., North Thames Dialysis Study (NTDS) Group. (2002) Clinical Outcomes and Quality of Life in Elderly Patients on Peritoneal Dialysis versus Hemodialysis. Peritoneal Dialysis International, 22, 463-470.

[11] Lamping, D.L., Constantinovici, N., Roderick, P., Normand, C., Henderson, L., Harris, S., et al. (2000) Clinical Outcomes, Quality of Life, and Costs in the North Thames Dialysis Study of Elderly People on Dialysis: A Prospective Cohort Study. The Lancet, 356, 1543-1550. http://dx.doi.org/10.1016/S0140-6736(00)03123-8

[12] Finkelstein, F.O., Afolalu, B., Wuerth, D. and Finkelstein, S.H. (2008) The Elderly Patient on CAPD: Helping Patients Cope with Peritoneal Dialysis. Peritoneal Dialysis International, 28, 449-451.

[13] Jassal, S.V., Chiu, E. and Hladunewich, M. (2009) Loss of Independence in Patients Starting Dialysis at 80 Years of Age or Older. The New England Journal of Medicine, 361, 1612-1613. http://dx.doi.org/10.1056/NEJMc0905289

[14] Tamura, M.K., Tan, J.C. and O’Hare, A.M. (2012) Optimizing Renal Replacement Therapy in Older Adults: A Framework for Making Individualized Decisions. Kidney International, 82, 261-269. http://dx.doi.org/10.1038/ki.2011.384

[15] Murtagh, F.E., Marsh, J.E., Donohoe, P., Ekbal, N.J., Sheerin, N.S. and Harris, F.E. (2007) Dialysis or Not? A Comparative Survival Study of Patients over 75 Years with Chronic Kidney Disease Stage 5. Nephrology Dialysis Transplantation, 22, 1955-1962. http://dx.doi.org/10.1093/ndt/gfm153

[16] Demoulin, N., Beguin, C., Labriola, L. and Jadoul, M. (2011) Preparing Renal Replacement Therapy in Stage 4 CKD Patients Referred to Nephrologists: A Difficult Balance between Futility and Insufficiency. A Cohort Study of $386 \mathrm{~Pa}-$ tients Followed in Brussels. Nephrology Dialysis Transplantation, 26, 220-226. http://dx.doi.org/10.1093/ndt/gfq372

[17] Kooman, J.P., Cornelis, T., van der Sande, F.M. and Leunissen, K.M. (2012) Renal Replacement Therapy in Geriatric End-Stage Renal Disease Patients: A Clinical Approach. Blood Purification, 33, 171-176. http://dx.doi.org/10.1159/000334153

\section{Abbreviations}

Arteriovenous fistula: AVF

Arteriovenous graft: AVG

End stage renal disease: ESRD

Hemodialysis: HD

Hemoglobin: (Hb)

Peritoneal dialysis: PD

Parathyroid hormone: PTH

Quality of life: QOL

Renal replacement therapy: RRT 